\title{
Theoretical Description for Chlorantraniliprole Electrochemical Determination, Assisted by Squaraine Dye Nano $\mathrm{Ag}_{2} \mathrm{O}_{2}$ Composite
}

\author{
Volodymyr V. Tkach ${ }^{1,2, *(D)}$, Marta V. Kushnir ${ }^{1}$, Sílvio C. de Oliveira ${ }^{2}$, Hanifa Zh. Salomova ${ }^{3}$, Yana G. \\ Ivanushko ${ }^{4}$, Oleksandra V. Ahafonova ${ }^{4}$, Mariia P. Mytchenok ${ }^{4}$, Petro I. Yagodynets ${ }^{1}$, \\ Zholt O. Kormosh ${ }^{5}$, Lucinda Vaz dos Reis ${ }^{6}$ \\ 1 Chernivtsi National University, 58000, Kotsyubyns'ky Str. 2, Chernivtsi, Ukraine \\ 2 Universidade Federal de Mato Grosso do Sul, Av. Sen. Felinto. Müller, 1555, C/P. 549, 79074-460, Campo Grande, MS, \\ Brazil \\ 3 Abu Ali Ibn Sino Bukhara State Medical Institute, 705018, Navoi Str., 1, Bukhara, Uzbekistan \\ 4 Bukovinian State Medical University, 58000, Teatral’na Sq. 9, Chernivtsi, Ukraine \\ 5 Eastern Ukrainian National University, 43000, Voli Ave., 13, Lutsk, Ukraine \\ 6 Universidade de Trás-os-Montes e Alto Douro, Quinta de Prados, 5001-801, Folhadela, Vila Real, Portugal \\ * Correspondence: nightwatcher2401@gmail.com;
}

Received: 8.08.2020; Revised: 5.09.2020; Accepted: 6.09.2020; Published: 11.09.2020

\begin{abstract}
The theoretical description for the chlorantraniliprole electrochemical determination, assisted by the hybrid composite of squaraine dye with $\mathrm{Ag}_{2} \mathrm{O}_{2}$ nanoparticles, has been described. The correspondent reaction mechanism has been proposed, and the correspondent mathematical model has been developed and analyzed by means of linear stability theory and bifurcation analysis. It has been shown that the chlorantraniliprole electrochemical anodic determination on high potential may be efficiently provided by silver (I, III) oxide nanoparticles, stabilized by the squaraine dye. On the other hand, the oscillatory and monotonic instability is also possible, being caused by DEL influences of the electrochemical stage.
\end{abstract}

Keywords: chlorantraniliprole; electrochemical sensors; squaraine dyes; copper sulfide; stable steady-state.

(C) 2020 by the authors. This article is an open-access article distributed under the terms and conditions of the Creative Commons Attribution (CC BY) license (https://creativecommons.org/licenses/by/4.0/).

\section{Introduction}

Chlorantraniliprole (Rynaxypyr, Fig. 1) is a selective insecticide of the ryanoid class [1 - 4]. It has been developed by DuPont in order to control a wide range of pests, including Lepidoptera, Coleoptera, Diptera, and Isoptera.

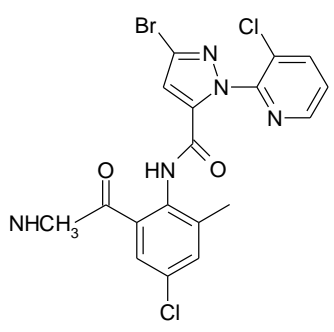

Figure 1. Chlorantraniliprole. 
In Uzbekistan, chlorantraniliprole is used as the active substance of zaragen pesticide [5 - 10]. It is characterized by high-level toxicity, including cardiovascular symptoms, like sinusoidal bradycardia. Moreover, this substance may be highly toxic to honey bees and aquatic organisms, which makes it an environmentally dangerous venom. Thus, the development of an efficient and rapid method for its determination is really actual [11 - 14], and the electroanalytical methods could be a very interesting solution for this problem.

For now, no works about the chlorantraniliprole electrochemical determination have been published. Nevertheless, its analogous molecules like carbendazim, isoproturon, paraquat, and diquat have been successfully determined by the electrochemical way [15-21]. Also, the chlorantraniliprole molecule contains the electroactive groups, the reason why it is considered electrochemically active.

Both anodic and cathodic electrochemical determination may be compatible with the chlorantraniliprole molecule. Although cathodic determination is preferable, the anodic oxidation is also possible and maybe efficient.

Nonetheless, the bare electrodes may not be suitable due to the high overvoltage needed to commence the electrochemical reaction. Thus the electrode must be chemically modified by a hybrid composite, possessing both the active substance and mediator.

This composite may contain inorganic oxidant nanoparticles as active substances, stabilized by organic conducting polymer [22-30], acting as a mediator.

Nevertheless, the organic electrooxidation processes (including the electropolymerization) tend to be accompanied by electrochemical instabilities. These instabilities include the oscillatory changes in electrochemical potential and monotonic instabilities [31 - 32] and influence the sensing properties of the composite.

Thus, in order to investigate the parameter values, correspondent to the most efficient monomer and polymer formation, also verify the possibility and probability of the electrochemical instabilities in this system, an a priori theoretical observation of the electrochemical determination.

So, in this work, a theoretical description for $\mathrm{Ag}_{2} \mathrm{O}_{2}-$ Squaraine Dye composite function in the electrochemical determination of chlorantraniliprole electrochemical determination is given. In order to realize it, we: suggest the mechanism of the reaction consequence, leading to the appearance of the analytical signal; develop the balance equation mathematical model, correspondent to the electroanalytical system; analyze and interpret the model in terms of the electroanalytical use of the system; seek for the possibility of electrochemical instabilities and for the factor, causing them; compare mentioned system's behavior with the similar ones [33-35].

\section{Materials and Methods}

The schematic representation of the mechanism for chlorantraniliprole electrochemical determination, assisted by nano- $\mathrm{Ag}_{2} \mathrm{O}_{2}$ - Squaraine Dye composite, is expressed on the Fig. 2.

Herein, silver (I, III) oxide is acting by a peroxide-like mechanism, transforming the pyridinic nitrogen atoms into $\mathrm{N}$-oxides. Nevertheless, the proper $\mathrm{Ag}_{2} \mathrm{O}_{2}$ isn't a peroxide, as none $\mathrm{O}-\mathrm{O}$ bonding is present in its molecule. The oxygen atom is expelled by a highly energetic trivalent silver atom, providing efficient analyte oxidation. A more branched mechanism with the possible phenolization and quinonization of the benzenic ring may be provided by a somehow more potent oxidant, like trivalent copper in alkaline media. 


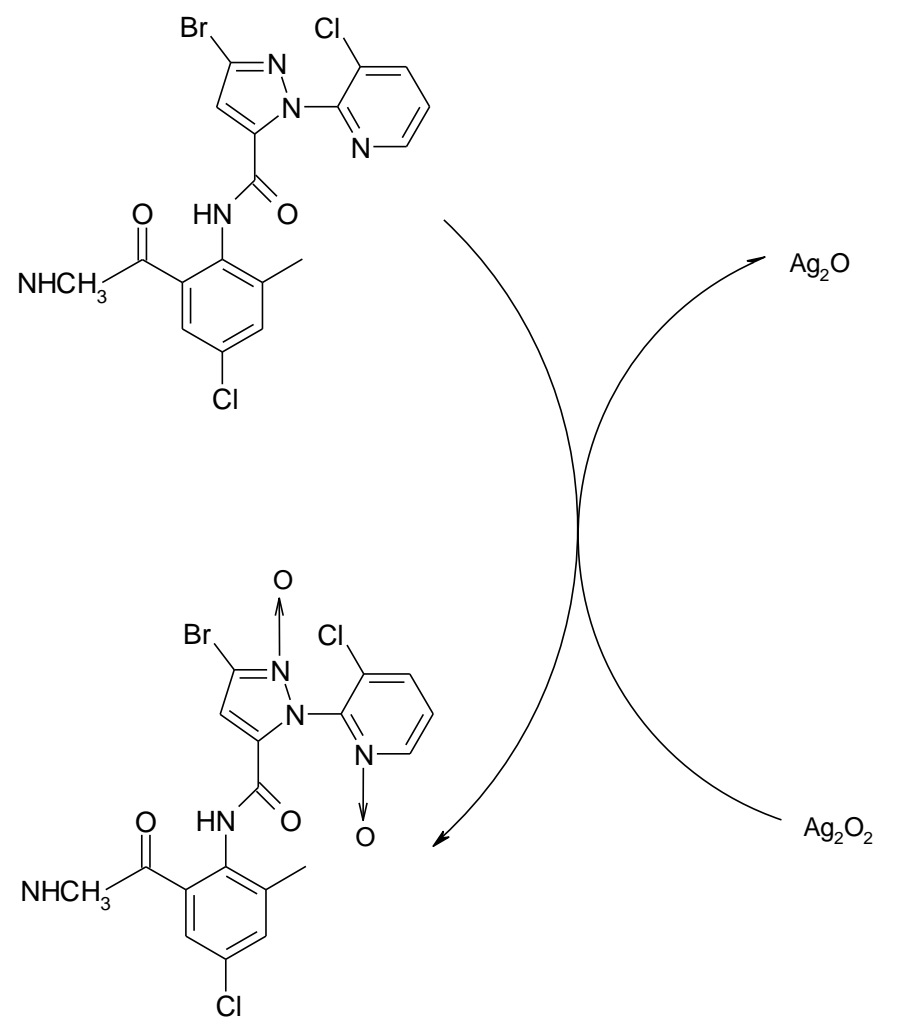

Figure 2. Chlorantraniliprole $\mathrm{Ag}_{2} \mathrm{O}_{2}$-assisted electrooxidation scheme.

There are two manners to describe, theoretically, the behavior of this system in potentiostatic mode (amperometric sensor). Either a bivariant or trivariant equation-set may be applied. In the last case, the N-oxidation of two pyridinic nitrogen atom is represented as a reaction sequence, as the super aromatic imidazolic ring is oxidized firstly. Therefore, in order to describe the electroanalytical system with the amperometric determination of chlorantraniliprole, assisted by $\mathrm{Ag}_{2} \mathrm{O}_{2}$ - Squaraine Dye composite, we introduce three variables: $\mathrm{c}$ - chlorantraniliprole concentration in the pre-surface layer; $\mathrm{c}^{*}$ - chlorantraniliprole - mono-N-oxide concentration in the pre-surface layer; s - silver (I) oxide surface coverage degree.

To simplify the modeling, we suppose that the reactor is intensively stirred, so we can neglect the convection flow. Also, we assume that the background electrolyte is in excess, so we can neglect the migration flow. The diffusion layer is supposed to be of a constant thickness, equal to $\delta$, and the concentration profile in it is supposed to be linear

It is possible to show that the system's behavior will be described by a trivariant differential-equation set (1):

$$
\left\{\begin{array}{c}
\frac{d c}{d t}=\frac{2}{\delta}\left(\frac{\Delta}{\delta}\left(c_{0}-c\right)-r_{O 1}\right) \\
\frac{d c^{*}}{d t}=\frac{2}{\delta}\left(r_{O 1}-r_{O 2}\right) \\
\frac{d s}{d t}=\frac{1}{S}\left(r_{O 1}+r_{O 2}-r_{2}\right)
\end{array}\right.
$$

Herein, $\mathrm{c}_{0}$ is the pesticide bulk concentration, $\Delta$ is its diffusion coefficient, $\mathrm{S}$ is the maximal silver (I) oxide matrix surface concentration, and the parameters $r$ are the correspondent reaction rates, which may be described as:

$$
r_{O 1}=k_{O 1} c(1-s)
$$




$$
\begin{aligned}
& r_{O 2}=k_{O 2} c *(1-s) \\
& r_{2}=k_{2} s \exp \left(\frac{2 F \varphi_{0}}{R T}\right)
\end{aligned}
$$

where $\mathrm{k}$ is the rate constants of the reactions, $\mathrm{F}$ is the Faraday number, $\varphi_{-} 0$ is the potential slope in DEL, relative to the zero-charge potential, $\mathrm{R}$ is the universal gas constant, and $\mathrm{T}$ is the absolute temperature.

In acidic media, the pyridinic nitrogen atoms would be protonated, causing a strong impact on the double electric layer (DEL). But in neutral and basic media, this impact won't be realized. Therefore, the behavior of this system will be more stable and less dynamic, as shown below.

\section{Results and Discussion}

In order to investigate theoretically the electroanalytical determination of chlorantraniliprole, assisted by squaraine dye $-\mathrm{Ag}_{2} \mathrm{O}_{2}$ composite, we analyze the equation-set (1) and algebraic relations $(2-3)$ by means of linear stability theory. The steady-state Jacobian matrix members will be described as:

$$
\left(\begin{array}{lll}
a_{11} & a_{12} & a_{13} \\
a_{21} & a_{22} & a_{23} \\
a_{31} & a_{32} & a_{33}
\end{array}\right)
$$

Herein,

$$
\begin{aligned}
& a_{11}=\frac{2}{\delta}\left(-\frac{\Delta}{\delta}-k_{O 1}(1-s)\right) \\
& a_{12}=0 \\
& a_{13}=\frac{1}{s}\left(k_{O 1} c\right) \\
& a_{21}=0 \\
& a_{22}=\frac{2}{\delta}\left(-k_{O 2}(1-s)\right) \\
& a_{23}=\frac{2}{\delta}\left(k_{O 2} c *\right) \\
& a_{31}=\frac{1}{s}\left(k_{O 1}(1-s)\right) \\
& a_{32}=\frac{1}{s}\left(k_{O 2}(1-s)\right) \\
& a_{33}=\frac{1}{S}\left(-c\left(k_{O 1}+k_{O 2}\right)-k_{2} \exp \left(\frac{2 F \varphi_{0}}{R T}\right)-j k_{2} s \exp \left(\frac{2 F \varphi_{0}}{R T}\right)\right)
\end{aligned}
$$

As in similar systems [33-35], the oscillatory behavior is possible in this system. Nevertheless, as on the chemical stages, no ionic compounds formation, destruction, and 
transformation occur (in basic media); the unique factor responsible for oscillatory behavior is the influence of the electrochemical stage on a double electric layer capacitance and conductivity. It is described by the positivity of the element $j k_{2} s \exp \left(\frac{F \varphi_{0}}{R T}\right)>0$ if $\mathrm{j}<0$. The oscillations are expected to be frequent and of small amplitude.

In order to investigate the steady-state stability, we apply the Routh-Hurwitz criterion to the equation-set (1). Avoiding cumbersome expressions, we introduce new variables and rewrite the determinant as (14):

$$
\frac{4}{\delta^{2} S}\left|\begin{array}{ccc}
-\kappa-\Xi & 0 & \Lambda \\
0 & -P & K \\
\Xi & P & -\Lambda-K-\Omega
\end{array}\right|
$$

Opening the brackets and applying the Det $\mathrm{J}<0$ requirements, salient from the criterion, we obtain the steady-state stability requirement, exposed as (15):

$$
\Lambda P \Xi-(\kappa+\Xi)(P \Lambda+P \Omega)<0
$$

Which may be rewritten as:

$$
\Lambda P \Xi<(\kappa+\Xi)(P \Lambda+P \Omega)
$$

defining an efficient, both diffusion and kinetically controlled electroanalytical system. The steady-state stability in this system is relatively high and is correspondent to the vast parameter region.

As in this case, there are no reactions capable of compromising the analyte and modifier stability; the steady-state stability is correspondent to the linear dependence between the chlorantraniliprole concentration and the current (in this system, we describe the amperometric sensor), which is therefore observed in vast measure of the concentrations.

The detection limit is relatively low, and it is correspondent to the margin between stable steady-states and unstable states. This margin is defined by the monotonic instability, described by the condition of Det $\mathrm{J}=0$, or:

$$
\Lambda P \Xi=(\kappa+\Xi)(P \Lambda+P \Omega)
$$

If the squaraine dye is substituted by a conducting polymer without pyridinic nitrogen atoms or other complex-forming groups, the model will be the same. On the other hand, the appearance of an autocatalytic reaction will enhance the probability of the oscillatory and monotonic instabilities.

\section{Conclusions}

From the analysis of the system with the chlorantraniliprole electrochemical determination as an anodic process, assisted by $\mathrm{Ag}_{2} \mathrm{O}_{2}-$ Squaraine Dye composite, it is possible to conclude that; The system's behavior is less dynamic, while compared to the similar systems, due to the less intense influence of the process of double electric layer conductivity and capacitance; The electroanalytical process tends to be either kinetically or diffusioncontrolled with the easy realization of linear dependence between the concentration and the current. The oscillatory behavior tends to have less probability of being realized, compared with similar systems, due to the impossibility of the DEL influence of the electrochemical stage. 


\section{Funding}

This research received no external funding.

\section{Acknowledgments}

This manuscript has no acknowledgment.

\section{Conflicts of Interest}

The authors declare no conflict of interest.

\section{References}

1. Suraphan, N.; Fan, L.; Baoxia, L.; Decheng, W. Co-delivery of chlorantraniliprole and avermectin with a polylactide microcapsule formulation. RSC Adv 2020, 10, 25418-25425, https://doi.org/10.1039/D0RA03825C.

2. Williams, J.R; Swale, D.R; Anderson T.D. Comparative effects of technical-grade and formulated chlorantraniliprole to the survivorship and locomotor activity of the honey bee Apis Melifera (L.) Pest. Manag. Sci., 2020, 76, 2582-2588, https://doi.org/10.1002/ps.5832.

3. Paramasivam, M. Dissipation kinetics, dietary and ecological risk assessment of chlorantraniliprole residue in/on tomato and soil using GC - MS. J. Food Sci. 2020, https://doi.org/10.1007/s13197-020-04573-5.

4. Redman, C.Z; Anastasio, C; Tjeerdema, R.S. Quantum yield for the aqueous photochemical degradation of chlorantraniliprole and simulation of its environmental fate in a model california rice field. Environmental Toxicology and Chemistry 2020, https://doi.org/10.1002/etc.4827.

5. Sunta, U; Prosenc, F; Trebse, P.; Bulc, T.G.; Kralk, M.B. Adsorption of acetamiprid, chlorantraniliprole and flubendiamide on different type of microplastics, present in alluvial soil. Chemosphere 2020, 261, https://doi.org/10.1016/j.chemosphere.2020.127762.

6. Parsaeyan, E.; Saber, M.; Safavi, S.A.; Poorjavad, N.; Biondi, A. Side effects of chlorantraniliprole, phosalone and spinosad on the egg parasitoid, Trichogramma brassicae. Ecotoxicology 2020, 29, 1052-1061, https://doi.org/10.1007/s10646-020-02235-y.

7. Ricupero, M.; Abbes, K.; Haddi, K.; Kurtulus, A.; Desneux, N.; Russo, A.; Siscaro, G.; Biondi, A.; Zappalà, L. Combined thermal and insecticidal stresses on the generalist predator Macrolophus pygmaeus. Science of The Total Environment 2020, 729, https://doi.org/10.1016/j.scitotenv.2020.138922.

8. Salomova, H.J.; Kosimov, H.O. Ecological-hygienic and safety parameters of the use of the zaragen insecticide in agriculture. Amer. J. Med. Med. Sci. 2020, 10, 266-268.

9. Bhattacharya, A.; Ghosh, K.; Chakraborty, S.; Hazra, R.; Ghosh, S. A Case of Suicidal Attempt with $\begin{array}{lllll}\text { Chlorantraniliprole. } & \text { Toxicology } & \text { International } & \mathbf{2 0 1 7}, & 22,\end{array}$ https://doi.org/10.22506/ti/2015/v22/i2/137674.

10. He, F.; Sun, S.; Tan, H.; Sun, X.; Qin, C.; Ji, S.; Li, X.; Zhang, J.; Jiang, X. Chlorantraniliprole against the black cutworm Agrotis ipsilon (Lepidoptera: Noctuidae): From biochemical/physiological to demographic responses. Scientific Reports 2019, 9, https://doi.org/10.1038/s41598-019-46915-0.

11. Zunic, A.; Vukovic, S.; Lazic, S; Sunjka, D.; Boskovic, D. The efficacy of novel diamide insecticide in Grapholita molesta suppresion and their residues in peach fruits. Plant Prot. Sci. 2020, 46-61, https://doi.org/10.17221/71/2019-PPS.

12. Mariappan, P.; Kaithamalai, B. Dissipation kinetics, decontamination and risk assessment of chlorantraniliprole in okra and soil under open field condition using GC-MS. International Journal of Environmental Analytical Chemistry 2020, https://doi.org/10.1080/03067319.2020.1772776.

13. Melo, M.G.; Carqueijo, A.; Freitas, A.; Barbosa, J.; Silva, A.S. Modified QuEChERS Extraction and HPLCMS/MS for Simultaneous Determination of 155 Pesticide Residues in Rice (Oryza sativa L.). Foods 2020, 9, https://doi.org/10.3390/foods9010018.

14. El-Mamy, M.A.M.; Osman, O.; Mahmoud, A.A.; Elhaes, H.; Gawad, A.E.D.A.; Ibrahim, M.A. Computational Notes on the Chemical Stability of Flutamide. Lett. Appl. Nanobiosci., 2020, 9, 1147-1155, https://doi.org/10.33263/LIANBS93.11471155.

15. Kumar, Y.; Vashistha, V.K.; Das, D.K. Synthesis of Perovskite-type $\mathrm{NdFeO}_{3}$ nanoparticles and used as electrochemical sensor for detection of paracetamol. Lett. Appl. Nanobiosci. 2020, 9, 866-869, https://doi.org/10.33263/LIANBS91.866869.

16. Long, X. Electrochemical Sensors with Antifouling Properties for Sensitive Detection of Isoproturon Based on Glassy Carbon Electrode Modified with Nafion Membrane. International Journal of Electrochemical Science 2020, 15, 4964-4977, https://doi.org/10.20964/2020.06.58. 
17. Sant'Anna, M.V.S.; Carvalho, S.W.M.M.; Gevaerd, A.; Silva, J.O.S.; Santos, E.; Carregosa, I.S.C.; Wisniewski, A.; Marcolino-Junior, L.H.; Bergamini, M.F.; Sussuchi, E.M. Electrochemical sensor based on biochar and reduced graphene oxide nanocomposite for carbendazim determination. Talanta 2020, 220, https://doi.org/10.1016/j.talanta.2020.121334.

18. Laghrib, F.; Bakasse, M.; Lahrich, S.; El Mhammedi, M.A. Electrochemical sensors for improved detection of paraquat in food samples: A review. Materials Science and Engineering: C 2020, 107, https://doi.org/10.1016/j.msec.2019.110349.

19. Pérez-Fernández, B.; Costa-García, A.; Muñiz, A.D. Electrochemical (Bio)Sensors for Pesticides Detection Using Screen-Printed Electrodes. Biosensors 2020, 10, https://doi.org/10.3390/bios10040032.

20. Xiang, H.; Cai, Q.; Li, Y.; Zhang, Z.; Cao, L.; Li, K.; Yang, H. Sensors Applied for the Detection of Pesticides and Heavy Metals in Freshwaters. Journal of Sensors 2020, 2020, https://doi.org/10.1155/2020/8503491.

21. Noori, J.S.; Mortensen, J.; Geto, A. Recent Development on the Electrochemical Detection of Selected Pesticides: A Focused Review. Sensors 2020, 20, https://doi.org/10.3390/s20082221.

22. Rezvani, J. Synthesis of $\mathrm{Ag}_{2} \mathrm{O}_{2}$ Semiconductor Micropowder by Plasma Electrolysis Method and Its Optical Characterization. Iran J. Cer Sci. 2020, 8, 69-79.

23. Lima, E.; Boto, E.R.; Ferreira, D.; Fernandes, J.R.; Almeida, P.; Ferreira, L.F.V.; Souto, E.B.; Silva, A.M.; Reis, V.L. Quinoline- and Benzoselenazole-Derived Unsymmetrical Squaraine Cyanine Dyes: Design, Synthesis, Photophysicochemical Features and Light-Triggerable Antiproliferative Effects against Breast Cancer Cell Lines. Materials 2020, 13, 2646-2660, https://doi.org/10.3390/ma13112646.

24. Gomes, V.S.D.; Gonçalves, H.M.R.; Boto, R.E.F.; Almeida, P.; Reis, L.V. Barbiturate squaraine dyes as fluorescent probes for serum albumins detection. Journal of Photochemistry and Photobiology A: Chemistry 2020, 400, https://doi.org/10.1016/j.photochem.2020.112710.

25. Butnarasu, C.; Barbero, N.; Barolo, C.; Visentin, S. Squaraine dyes as fluorescent turn-on sensors for the detection of porcine gastric mucin: A spectroscopic and kinetic study. Journal of Photochemistry and Photobiology B: Biology 2020, 205, https://doi.org/10.1016/j.jphotobiol.2020.111838.

26. Maeda, T.; Liess, A.; Kudzus, A.; Krause, A.-M.; Stolte, M.; Amitani, H.; Yagi, S.; Fujiwara, H.; Würthner, F. Hydrogen bond-rigidified planar squaraine dye and its electronic and organic semiconductor properties. Chemical Communications 2020, 56, 9890-9893, https://doi.org/10.1039/D0CC04306K.

27. Chen, Y.; Wang, S.; Li, Z. A cobalt-pyrrole coordination compound as high performance cathode catalyst for direct borohydride fuel cells, RSC Adv., 2020, 29119 - 29127, https://doi.org/10.1039/D0RA05143H.

28. Aguilera, L.; Aguiar, P.C.M.; Ruiz, Y.L.; Almeida, A.; Moreira, J.A.; Passos, R.R.; Pocrifka, L.A. Electrochemical synthesis of $\gamma-\mathrm{CoOOH}$ films from $\alpha-\mathrm{Co}(\mathrm{OH}) 2$ with a high electrochemical performance for energy storage device applications. Journal of Materials Science: Materials in Electronics 2020, 31, 30843091, https://doi.org/10.1007/s10854-019-02853-1.

29. Shamraiz, U.; Badshah, A.; Raza, B. Ultrafine $\alpha-\mathrm{CoOOH}$ Nanorods Activated with Iron for Exceptional Oxygen Evolution Reaction. Langmuir 2020, 36, 2223-2230, https://doi.org/10.1021/acs.langmuir.9b03293.

30. Ruiter, F.A.A.; Sidney, L.E.; Kiick, K.L.; Segal, J.I.; Alexander, C.; Rose, F.R.A.J. The electrospinning of a thermo-responsive polymer with peptide conjugates for phenotype support and extracellular matrix production of therapeutically relevant mammalian cells. Biomaterials Science 2020, 8, 2611-2626, https://doi.org/10.1039/C9BM01965K.

31. Das, I.; Goel, N.; Agrawal, N.R.; Gupta, S.K. Growth patterns of dendrimers and electric potential oscillations during electropolymerization of pyrrole using mono-and mixed surfactants. 2010, 114, 1288812896, https://doi.org/10.1021/jp105183q.

32. Das, I.; Goel, N.; Gupta, S.K.; Agrawal, N.R. Electropolymerization of pyrrole: Dendrimers, nano-sized patterns and oscillations in potential in presence of aromatic and aliphatic surfactants. Journal of Electroanalytical Chemistry 2012, 670, 1-10, https://doi.org/10.1016/j.jelechem.2012.01.023.

33. Tkach, V.V.; Storoshchuk, N.M.; Romaniv, L.V.; De Oliveira, S.C.; Luganska, O.V.; Gala, H.B.; Tchikuala, E.F.; Yagodynets, P.I. The theoretical evaluation of the poly (3, 4'dimetylpyrrole) cathodic electrodeposition assisted by manganate ions. Vietnam. J. Chem.. 2018, 56, 440-444, https://doi.org/10.1002/vjch.201800027.

34. Tkach, V.V.; Kushnir, M.V.; Ivanushko, Y.G.; de Oliviera, S. The Theoretical Description for Neotame Electrochemical Determination, Assisted by Vanadium Oxyhydroxide Composite with a Squarainic Dye. Appl. J. Env. Eng. Sci. 2020, 6, 109-115.

35. Tkach, V.V.; Kushnir, M.V.; Storoshchuk, N.M.; Ivanushko, Y. The Theoretical Description for the Confection of the Novel Thiourea-Based Active Surface for Cathodic Conducting Polymer Deposition. Appl. J. Env. Eng. Sci. 2020, 6, 143-148. 